\title{
Cultivo de microalgas Isochrysis galbana y Nannochloropsis sp. para alimentación de larvas de peces marinos
}

\section{Cultivation of microalgae Isochrysis galbana and Nannochloropsis sp. for feeding marine fish larvae}

María Fernanda Pereira Gutiérrez
Universidad de Bogotá Jorge Tadeo Lozano, Bogotá, D. C., Colombia

http://orcid.org/0000-0003-3291-8214

mariaf.pereirag@utadeo.edu.co

Guiomar Aminta Jáuregui Romero

Universidad de Bogotá Jorge Tadeo Lozano, seccional Santa Marta, Colombia

http://orcid.org/0000-0003-1239-7933

Adrián Devia Barros

Centro de Investigación, Educación y Recreación (Ceiner), Cartagena de Indias, Colombia

Jaime Rojas Ruiz

Centro de Investigación, Educación y Recreación (Ceiner), Cartagena de Indias, Colombia

Fecha de recepción: 5 de julio de 2017

Fecha de aceptación: 2 de octubre de 2017

Sugerencia de citación: Pererira Gutiérrez, M. F., Jáuregui Romero, G. A., Devia Barros, A. y Rojas Ruiz, J. (2017). Cultivo de microalgas Isochrysis galbana y Nannochloropsis sp. para alimentación de larvas de peces marinos. Mutis, 7(2), 81-85, doi: http://dx.doi.org/10.21789/22561498.1246

Editor: Hernández Fernández, J. javier.hernandez@utadeo.edu.co

\section{RESUMEN}

En la producción de alimento vivo, representado principalmente por microalgas, se buscan nuevas técnicas de medios de cultivo para sustituir las fórmulas tradicionales en aras de reducir costos. Teniendo en cuenta esto, se usó un medio no convencional (fertilizantes industriales) para producir las microalgas Isochrysis galbana y Nannochloropsis sp. en cultivos estáticos, y se alcanzaron densidades de 7,5 $\times 10^{6} \mathrm{cel} \mathrm{mL}^{-1}$ de Nannochloropsis sp. en $1000 \mathrm{~L}$ y $0,265 \times 10^{6} \mathrm{cel} \mathrm{mL} \mathrm{m}^{-1}$ de l. galbana en $250 \mathrm{~L}$. Hubo un crecimiento exponencial, que se alcanzó entre los tres y los ocho días, en que se duplicaron las densidades iniciales. Se sugiere cosechar en lapsos cortos (hasta cuatro días), debido a la proliferación de contaminantes y la disminución de la calidad de las células con el tiempo. Se concluye que el medio diseñado para el enriquecimiento del cultivo es una alternativa viable para la producción de las microalgas que permite satisfacer la demanda alimenticia en el levante de larvas de peces marinos.

Palabras clave: cultivo estático, medio no convencional, fertilizantes agrícolas, Isochrysis galbana, Nannochloropsis sp. 


\section{ABSTRACT}

In the production of live food, represented mainly by microalgae, this seeks new techniques of culture media, with the substitution of traditional formulas, in favor of a reduce costs. Unconventional medium (industrial fertilizers) was used to produce the microalgae Isochrysis galbana and Nannochloropsis sp. from static cultures, reaching densities of 7,5 $\times 10^{6}$ cells mL $\mathrm{m}^{-1}$ of Nannochloropsis sp. in $1000 \mathrm{~L}$ and $0,265 \times 10^{6}$ cells $\mathrm{mL}^{-1}$ of I. galbana in $250 \mathrm{~L}$. Exponential growth was achieved between 3 and 8 days, doubling the initial densities. It is suggested to harvest in short periods (up to 4 days), due to the proliferation of contaminants such as protozoa and bacteria, and decrease the quality of the cells over time. It is concluded that the medium designed for the enrichment of the crop, is a viable alternative for the production of microalgae, allowing to satisfy the food demand in the raising of marine fish larvae.

Keywords: Static culture, unconventional medium, agricultural fertilizers, Isochrysis galbana, Nannochloropsis sp.

\section{INTRODUCCIÓN}

En el desarrollo larvario de peces es esencial tener un laboratorio destinado a la producción y mantenimiento de variedad de alimento vivo, denominado cultivos auxiliares o de presas vivas, alimento representado principalmente por microalgas (Barrera, De Lara, Castro, Castro y Malpica, 2003). En estos cultivos, los reactivos empleados, la mano de obra calificada y la infraestructura adecuada representan altos costos, lo que hace necesario estandarizar nuevas técnicas y medios de cultivo que reduzcan los costos de producción (Nieves, Voltolina, López, Cisneros y Piña, 2000).

Las microalgas (fitoplancton) aportan polisacáridos, aminoácidos, enzimas y proteínas que varían en cantidad según la especie, por lo que son implementadas como mezcla para satisfacer todos los requerimientos nutricionales de organismos en cultivo como peces y crustáceos (Barrera et al., 2003). Así, la Nannochloropsis sp. tiene células pequeñas redondeadas de 2 a $4 \mu \mathrm{m}$ sin flagelos, sin contenido de DHA, pero con altas concentraciones de EPA, proteínas y carbohidratos (Velasco, Carrera y Barros, 2008). Por otro lado, la Isochrysis galbana es una microalga con células ovoides de 5 a $7 \mu \mathrm{m}$, con dos flagelos y rica en DHA, benéfico para el crecimiento y desarrollo de larvas de peces marinos (Coutteau, 1996) y zooplancton (Hoff y Snell, 1993).

Ante la dificultad del sector de la acuicultura marina de lograr un abastecimiento adecuado de juveniles (semillas), y dada la continuidad de los sistemas de producción, es necesario mantener la cantidad suficiente de alimento de calidad que requieren los cultivos de peces, implementando nuevos medios de enriquecimiento y minimizando costos, sin que ello atente contra una alta producción. El presente estudio tuvo como objetivo probar un medio no convencional para masificar I. galbana y Nannochloropsis sp., enfocado en la alimentación de larvas de peces marinos.

\section{MATERIALES Y MÉTODOS}

Los cultivos de microalgas marinas se realizaron en el Laboratorio de Acuicultura, en el área de Alimento Vivo del Centro de Investigación, Educación y Recreación, en Cartagena, Colombia. Las cepas de I. galbana y Nannochloropsis sp. fueron adquiridas en Ceniacua (Cartagena, Colombia). Para el enriquecimiento de estas se utilizó el medio no convencional compuesto por fertilizantes agrícolas: $0,02 \mathrm{~mL}$ nutrifoliar completo, $0,065 \mathrm{~g}$ de urea, $0,05 \mathrm{~mL}$ de triple 15 y $1 \mathrm{~mL}$ de vitamina (neurobión y complejo B) por cada litro de agua de mar filtrada, autoclavada para volúmenes menores y clorada para volúmenes mayores.

Las microalgas se cultivaron en el medio enriquecido mediante una serie de incremento de volúmenes: 10 $\mathrm{mL}, 250 \mathrm{~mL}, 500 \mathrm{~mL}, 2 \mathrm{~L}, 15 \mathrm{~L}, 30 \mathrm{~L}, 250 \mathrm{~L}$ y $1000 \mathrm{~L}$. La tasa de crecimiento y los tiempos de siembra se calcularon utilizando la ecuación de velocidad específica $(\mu)$ a partir de la concentración celular (expresada como el número de células por mililitro) de muestras 
diarias de cada volumen de siembra. Se registró la calidad de las células (movilidad, forma y presencia de contaminantes) durante ocho días con un microscopio compuesto, una cámara de Neubauer de 0,1 mm de profundidad, y la ecuación (1) utilizada para evaluar dichos datos,

$$
\mu=\frac{\frac{\ln \left(\frac{N_{t 2}}{N_{t 1}}\right)}{\ln (2)}}{t_{2}-t_{1}}(1)
$$

donde $N_{t 2}$ y $N_{t 1}$ es la concentración celular registrada al inicio y al final de un intervalo de tiempo $(t)$. Esta ecuación permite identificar la fase exponencial como aquella en la que la velocidad de crecimiento adquiere su valor máximo, tiempo propicio para la cosecha, después del cual las condiciones son subóptimas (Arredondo y Voltolina, 2007).

\section{RESULTADOS Y DISCUSIÓN}

Los fertilizantes agrícolas se consideran una alternativa económica para reducir los costos de producción. En un cultivo estático de microalgas, y hasta $20 \mathrm{~L}$, es recomendable el uso de medios analíticos, pues los medios no convencionales o simplificados pueden afectar el crecimiento de la microalga y su composición cambiando el contenido de varias fracciones orgánicas (Peraza, 1997). En este estudio fue una alternativa que permitió satisfacer la demanda alimentaria de los primeros estadios de las larvas. Transcurridos cuatro días de la inoculación o siembra, los resultados fueron visibles en número y calidad de las células de I. galbana y Nannochloropsis sp. (figura 1, a y b): alcanzaron densidades de $7,5 \times 10^{6} \mathrm{cel} \mathrm{mL}^{-1}$ de Nannochloropsis sp. en $1000 \mathrm{~L}$ y $0,265 \times 10^{6} \mathrm{cel} \mathrm{\textrm {mL } ^ { - 1 }} \mathrm{de} I$. galbana en $250 \mathrm{~L}$.

Figura 1. Cultivo de células después de cuatro días de la siembra en medio no convencional. a. I. galbana. b. Nannochloropsis sp.

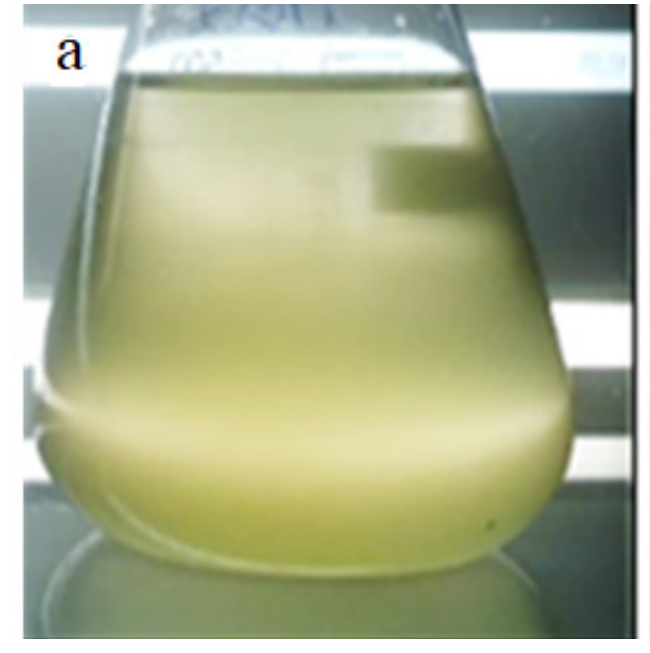

En Piña, Medina, Nieves, Leal, López y Guerrero (2007), cuando se trabajó con Isochrysis sp. y los medios F/2 de Guillard y Ryther, urea y Nutrilake, no se encontraron diferencias significativas en la densidad celular de los tratamientos. Se obtuvieron mayores concentraciones con fertilizantes comerciales, similares a los registrados por Nieves, Voltolina, López, Cisneros y Piña (2000), quienes enriquecieron las micro-

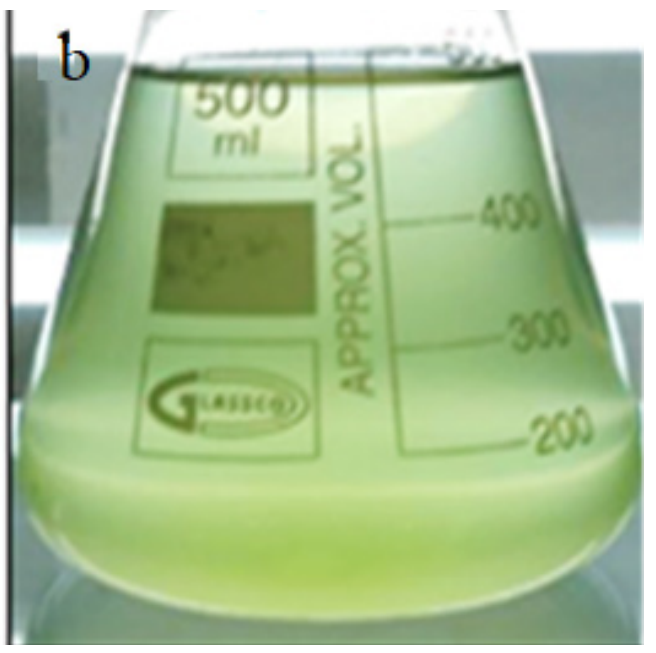

algas con productos de naturaleza zeolítica (PNZ). Sin embargo, en estos estudios se trabajó sobre cultivos a gran escala y no en cultivo estático. En contraste, Valenzuela, Lafarga, Millán y Núñez (2005) trabajaron con Rhodomonas sp., evaluaron el crecimiento y composición en cultivo estático con F/2 de Guillard y Ryther y fertilizantes agrícolas, y observaron un crecimiento no diferencial en ambos medios y una leve 
disminución en las fracciones de carbohidratos y lípidos en la fase exponencial.

Esto permite inferir que el medio no convencional trabajado es una alternativa para la maricultura, no solo por las densidades alcanzadas, sino por el sostenimiento del cultivo o stocks, sin afectar el siguiente eslabón de producción (zooplancton y larvas de peces).

A pesar de las medidas tomadas para el manejo del cultivo desde el cepario de Nannochloropsis sp. y en volúmenes mayores a 2 L en I. galbana, la contaminación por protozoarios y bacterias fue recurrente: al menos el $30 \%$ en el cepario y un $50 \%$ en volúmenes mayores. Las fuentes de contaminación incluyen el sistema de aireación, los nutrientes, insectos, el agua, la cristalería y los tanques de siembra (Hoff y Snell, 1993). La intensidad lumínica y la temperatura son los factores de mayor incidencia en la fotosíntesis y en el crecimiento de las microalgas, pero también influyen en los contaminantes biológicos (bacterias, zooplancton, virus y microalgas). Los ajustes de estos aspectos al rango óptimo de las microalgas desmejorarán los riesgos de contaminación (Wang, Zhang, Chen, Wang y Liu, 2013).

Partiendo de inóculos con densidades no mayores a dos millones de cel $\mathrm{mL}^{-1}$ de I. galbana, la fase exponencial de crecimiento se alcanzó entre el tercero y el séptimo día, plazo en se llegó a duplicar la concentración inicial. Los diferentes volúmenes de siembra adquirieron su tonalidad característica (dorado o amarillo un poco oscuro) al tercer y cuarto día. Después de este tiempo dicho color se fue perdiendo, formando un precipitado marrón en el fondo, que indica muerte celular. Se determinó proceder a la inoculación en el día séptimo; sin embargo, la calidad de la cepa de $I$. galbana no fue la mejor, debido a que presentó poca movilidad y células irregulares. Asimismo, la cantidad de competidores, como bacterias y protozoos, aumentó, y un mayor tiempo de transferencia (siembra) de un volumen a otro condjujo a la caída del nivel superior en un tiempo menor. Algo similar ocurrió con la Nannochloropsis sp.: partiendo de densidades mayores a tres millones de cel $\mathrm{mL}^{-1}$ se alcanzó la fase exponencial entre tres y ocho días. El objetivo de cultivar microalgas es alcanzar densidades celulares más altas en periodos cortos de tiempo (Creswell, 2010).
Cuando las células del inóculo no se encuentran en condiciones metabólicas adecuadas, la reproducción se hace más lenta, por lo cual el cultivo no será exitoso (Arredondo y Voltolina, 2007). La microalga, desde el cultivo estático presenta contaminación por protozoarios, lo que afecta el metabolismo por la competencia generada; eso explica la lentitud para alcanzar la fase exponencial.

\section{CONCLUSIONES}

El medio diseñado resultó ser una alternativa viable para la producción de las microalgas, desde el cultivo estático, algo que se refleja en la calidad y densidad

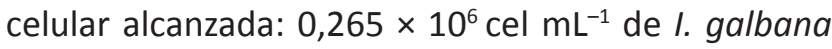
en $250 \mathrm{~L}$ y $7,5 \times 10^{6} \mathrm{cel} \mathrm{mL}^{-1}$ de Nannochloropsis sp. en $1000 \mathrm{~L}$.

Los tiempos de transferencia de los inóculos no deben sobrepasar los cuatro días. Transcurrido este tiempo, la viabilidad de las células decae y son más afectadas por contaminantes como protozoos y bacterias, que afectan la calidad del cultivo y el siguiente eslabón de producción.

\section{AGRADECIMIENTOS}

Los autores agradecen a las directivas del Centro de Investigación, Educación y Recreación por permitir el uso de sus instalaciones, material y equipo, y al profesor Javier Hernández por la crítica del documento.

\section{REFERENCIAS}

Arredondo, B y Voltolina, D. (2007). Concentración, recuento celular y tasa de crecimiento. En Arredondo y Voltolina (eds.), Métodos y herramientas analíticas en la evaluación de la biomasa microalgal. México: Centro de Investigaciones Biológicas del Noroeste, S.C. La Paz, B.C.S., pp. 22-29.

Barrera, T., De Lara, R., Castro, G., Castro, J., y Malpica, A. (2003). Alimento vivo en la acuicultura. ContactoS, 48, 27-33. 
Coutteau, P. (1996). Micro-algae. En P. Lavens y P. Sorgeloos (eds.), Manual on the production and use of live food for aquaculture. FAO. Fisheries Technical Paper, 361, 295.

Creswell, L. (2010). Phytoplankton culture for aquaculture feed. Southern Regional Aquaculture Center, 5004, 16.

Hoff, F. H. y Snell, T. W. (1993). Plankton culture manual. 3. a ed. Florida: Florida Agua Farms, Inc., p. 147.

Nieves, M., Voltolina, D., López, J., Cisneros, M., y Piña, P. (2000). Cultivo de microalgas marinas con medios enriquecidos con productos de naturaleza zeolítica. Hidrobiológica, 10(1), 1-16.

Peraza, D. M. (1997). Cultivos de la diatomea Chaetoceros sp. con tres fertilizantes agrícolas. Tesis de técnico en acuicultura. Universidad Autónoma de Sinaloa, México.

Piña, P., Medina, M. A., Nieves, M., Leal, S., López, J. y Guerrero, M. (2007). Cultivo de cuatro especies de microalgas con diferentes fertilizantes utilizados en acuicultura. Rev. Invest. Mar, 28(3), 225-236.
Valenzuela Espinosa, E., Lafarga de la Cruz, F., Millán Núñez, R. y Núñez Cebrero, F. (2005). Crecimiento, consumo de nutrientes y composición proximal de Rhodomonas sp. cultivada con medio $f / 2$ y fertilizantes agrícolas. Ciencias Marinas, 31(1A), 79-89.

Velasco, L. A., Carrera, S. y Barros, J. (2008). Producción de microalgas como alimento para pectínidos. En L. A. Velasco (ed.), Biología y cultivo de los pectínidos de interés comercial de Colombia. Santa Marta: Editorial Unimagdalena, pp. 31-63.

Wang, H., Zhang, W., Chen, L., Wang, J. y Liu, T. (2013). The contamination and control of biological pollutants in mass cultivation of microalgae. Bioresource Technology, 128, 745750. 